Review Article

\title{
SOCIO-CULTURAL PERSPECTIVES ON HEALTH AND ILLNESS
}

\author{
Malathi G. Nayak', Sharada', Anice Geroge ${ }^{3}$ \\ M anipal University, Manipal. \\ Correspondence: \\ Ms. Malathi G. Nayak, \\ Assistant Professor in Community Health Nursing Department, \\ M anipal College of Nursing, M anipal University, M anipal. \\ Mobile : +9194495 86431 E-mail: malathi.nayak@manipal.edu
}

Assistant Professor ${ }^{1}$ in Community Health Nursing Department, Assistant Lecturer ${ }^{2}$, Dean ${ }^{3}$, Manipal College of Nursing,

\section{Abstract:}

Introduction: Every society has its own traditional beliefs and practices related to health care. Some practices are effective whereas others may be harmful or ineffective. These beliefs and practices are linked to culture, environment and education. Health workers must have concern for the community's cultural values and beliefs so that they can utilize the harmless practices for effective use as well as eliminate harmful practices. Objectives of the study were to explore the adults perception on health and illness, Identify the health care seeking behavior and to find the relationship between perceptions on health and illness with the study variables.

Method: Explorative cross sectional survey study was conducted among rural adults in the selected villages of Udupi district. The study subjects (75) were interviewed through a questionnaire and selected by purposive sampling

Results: Data shows that majority (52.9\%) of them were in the age group of $20-40$ years and most ( $76.6 \%$ ) of them were females. $52 \%$ were illiterate and $73 \%$ were lived in nuclear family. $64 \%$ of the samples take the decision to seek medical help by themselves. M ajority of the samples ( $85 \%$ ) perceived that yoga and exercises reduces the health risks. M ost of the samples (70\%) perceived smoking, alcohol, using unsafe water \& food, multiple sex partner, stress, obesity, are the risk factors to cause the diseases.

Conclusion: Present study samples perceived diseases like epilepsy, tuberculosis, leprosy is due to sin of god and past sins. Further studies may require giving awareness program on particular area to remove such false beliefs.

Keywords: Perception on health and illness, health care seeking behavior, perceived health risks.

\section{Introduction:}

Every society has its own traditional beliefs and practices related to health care.

Beliefs in supernatural powers, i.e. God, beliefs in holy rituals, salvation,

offerings and sacrifices are applied at different stages of life from birth to death.

\section{Background of The Problem:}

People have taken pleasure in using traditional beliefs and practices for a long time and got used to it. Thus it can be

\begin{tabular}{|c|}
\hline Access this article online \\
\hline Quick Response Code \\
\hline
\end{tabular}
made easily acceptable something that has been given by the faith healer to the community. Some practices are effective whereas others may be harmful or ineffective. These beliefs and practices are linked to culture, environment and education. Health workers must have concern for the community's cultural values and beliefs so that they can utilize the harmless practices for effective use as well as eliminate harmful practices $^{1}$

All people, whether rural or urban, have their own beliefs and practices concerning health and diseases. Not all customs and beliefs are bad, some are have positive values while other may be harmful. Social and psychosocial factors increase the risk of illness and influence the way that a person defines and reacts to illness. Social variable partly determine how the health care system provides medical care. Cultural background influences entry into the health care system and personal health practices. The ideas of the individuals may be valid and certainly influence their health care behavior. Health professionals must recognize the existence of relativism in regard to modern scientific medicine. Socio cultural differences between families and 
nurses can affect the nurse-patient, family relationship and quality of care delivered. To provide the most effective care the nurse needs to understand the relationship of different needs and the cultural factors that determine the priorities for the family ${ }^{2}$.

Culture refers to the values, beliefs, and behaviors that are shared by members of a society and which provide direction for people as to what is acceptable or unacceptable in given situations. Because even the smallest decisions of a person's everyday life are influenced by culture, quality health care cannot be provided without a consideration of the client's cultural background.

M uch research has focused on how persons come to make judgments of their own health status. Many studies suggest that judgments of health and well-being and interpretations of sickness are shaped by factors beyond those traditionally captured by biomedical conceptions of illness. The identification of the exact psychological and social factors responsible for self-assessed health, however, remains elusive. Some have suggested that individuals take into account important social and psychological resources, such as social support, feelings of control, and optimism, when making judgments of their own health-and that these psychosocial resources provide protection against morbidity and mortality ${ }^{3}$.

Health and illness behaviour studies make clear that the forces affecting health and treatment outcomes transcend medical care and the transactions that takes place between doctor and patient. Studies of health and illness behaviour teach the importance of moving beyond initial complaints and narrow definitions of problems and toward examining the broad context of individuals' lives and the factors that affect social functioning and quality of life. A medical care system responsive to these broad concerns would be better prepared for the impending health care challenges of the new millennium. The literature of lay beliefs suggests that the concepts significantly affect a population's health and illness behaviours, health consciousness and risk perceptions. Therefore, a growing emphasis is now being placed on detecting lay beliefs of health, disease and risks.
Health perceptions and health beliefs vary across the lifespan. ${ }^{4}$

Sociologists have demonstrated that the spread of diseases is heavily influenced by the socioeconomic status of individuals, ethnic traditions or beliefs, and other cultural factors. The prevalence and response to different diseases varies by culture. Sociologists agree that alcohol consumption, smoking, diet, and exercise are important issues, but they also see the importance of analyzing the cultural factors that affect these patterns. Social factors play a significant role in developing health and illness. Herbal treatment is one of the primary medicines used to treat HIV in Africa. The study of hypertension within the United Kingdom has turned to examining the role that beliefs play in its diagnosis and treatment. There were differing reasons for non-compliance that involve the patient's perception and beliefs about the diagnosis. Patients commonly believe that high levels of anxiety when first diagnosed are the major cause and think that when stress levels decline so to 0 will their hypertension ${ }^{5}$. Limited knowledge about DM, based on beliefs about health and illness including biomedical and traditional explanations related to the influence of supernatural forces, e.g. fate, God etc., were found, which affected patients' self-care and care-seeking behaviour ${ }^{6}$.

\section{Statement of The Problem:}

An explorative study to assess the socio-cultural perspectives on health and illness among adults of rural areas of Udupi district.

\section{Purpose of The Study:}

The present study extends existing research by broadening the focus from examining concepts on health and illness. The aim of the present study is to explore beliefs about health and illness that might affect self-care practice and health-care-seeking behaviour among adults who live in selected villages.

\section{Objectives of The Study:}

The objectives of the study were to

1. Explore the perception on health and illness among adults 
2. Identify the health care seeking behavior

3. Determine the perceived health risk among adults.

4. Find the association between perceived score on health and illness and selected variables.

\section{Variables:}

Key variables - Perception on health and illness, health care seeking behavior, perceived health risks.

Selected variables - Age, gender, religion, type of family, education, occupation, exposure to mass media, income of the family.

\section{Delimitation:}

The study is delimited to adults of selected villages of Udupi District

\section{Research Methodology :}

A community based explorative cross sectional survey study was carried out in Hirebettu village of $U$ dupi District. A non probability purposive sampling was used to select 75 adults by using structured and validated questionnaire on perception on health \& illness, perceived health risks and on health seeking behavior.

The Inclusion criteria a adults who were aged about 25yrs and above, living and working in village area, present at home during the time of study and willing to participate.

Demographic Proforma consisted of age, gender, religion, type of family, education, occupation, exposure to mass media, income of the family. Perceived health and illness tool had 36 items on likert scale and categorized as low perception (<48), average perception (49-96) and high perception (>96). Perceived health risks had 27 risk factors and were categorized as high risk ( $>54)$, moderate risk(28$54)$ and low risks $(<27)$ and health seeking behavior had total 5 items.

Validity of the tools were established by submitting to five experts and there was $100 \%$ agreement on all items with minimal correction. Reliability was established by administering the tool to ten adults, reliability coefficient of the tools were computed by using chronbach's alpha and was $(\alpha=0.82)$. Administrative permission was obtained to collect the data from the concerned authorities. The data was collected after obtaining the written consent from the eligible participants. The data was analyzed using descriptive (frequency and percentage) and inferential statistics. The analysis was done based on objectives and hypothesis by using SPSS package version 16 .

\section{Results}

\section{Sample characteristics:}

Among 75 adults, majority (69.3\%) of them were in the age group of $25-40$ years and $66.7 \%$ of them were females, $90 \%$ were belongs to Hindu religion and living in a nuclear family. Majority of the adults received information from the health personnel and from mass media (Table 1). The study showed that majority of them had perceived their health status as average, decision taking by self to seek the medical help and availing the treatment from the private clinics. M ost of the adults reported reasons for not seeking help that diseases are not sever enough (70.7\%), unable to pay medical expenses (62.7\%). Majority of the adults perceived that when they feel sick then only they approach (90\%) health care (Table 2). Results shows that $84 \%$ of adults have high perception and $16 \%$ of adults have average perception on health and illness (Fig 1) and $45 \%$ of adults believe that disease are caused by wrath of the god/goddess, $26 \%$ of them reported leprosy/TB caused due to their past sins, $48 \%$ believed that epilepsy are due to ghost intrusion, 38\% had given the report illness can be traced by enemies and $36 \%$ adults perceived that diseases are caused by their 'karma' (Table 3). The Mean and Standard Deviation of Perception on health and illness was 104.97 and 12.44 respectively.

The data shows that adults of rural areas, they perceived that smoking, alcohol intake, drug abuse, using unsafe water and food and multiple sex partners were the high risk for the health and illness (Table 4). The M ean and Standard Deviation of perceived health risk was 59.32 and 7.79 respectively. Chi-square was computed to analyze the association between perceived health \& illness and selected variables, results shows that there is a no significant association between perception on health and 
illness and selected variables. Thus the null hypothesis was accepted on regard to these variables and alternative hypothesis was rejected (Table 5).

\section{Discussion and conclusion :}

In the present study $45 \%$ of adults believe that disease are caused by wrath of the god/goddess this supports the study findings by Katarina Hjelm, Karin Bard, Per Nyberg and Jan Apelqvist explaining the cause of Diabetes M ellitus (DM) as 'the will of Allah or God'.

The spread of diseases is heavily influenced by the socioeconomic status of individuals, ethnic traditions or beliefs, and other cultural factors. Results shows that

Table 1: Sample Characteristics

\begin{tabular}{|c|c|c|c|}
\hline \multicolumn{2}{|c|}{ SI.No Category } & $f$ & $\%$ \\
\hline \multirow[t]{4}{*}{1} & Age in years & & \\
\hline & $25-40$ & 52 & 69.3 \\
\hline & $41-60$ & 22 & 29.3 \\
\hline & $>60$ & 1 & 1.3 \\
\hline \multirow[t]{3}{*}{2} & Gender & & \\
\hline & Male & 25 & 33.3 \\
\hline & Female & 50 & 66.7 \\
\hline \multirow[t]{4}{*}{3} & religion & & \\
\hline & Hindu & 68 & 90.7 \\
\hline & M uslim & 6 & 8.0 \\
\hline & Christian & 1 & 1.3 \\
\hline \multirow[t]{4}{*}{4} & M arital status & & \\
\hline & Married & 62 & 82.7 \\
\hline & Unmarried & 8 & 10.7 \\
\hline & Widow & 5 & 6.7 \\
\hline \multirow[t]{5}{*}{5} & Educational status & & \\
\hline & Primary $\left(>5^{\text {th }} \mathrm{std}\right)$ & 22 & 29.3 \\
\hline & Primary $\left(5^{\text {th }}\right.$ to $\left.7^{\text {th }} \mathrm{Std}\right)$ & 17 & 22.7 \\
\hline & secondary & 36 & 48.0 \\
\hline & Type of family & & \\
\hline \multirow{3}{*}{6.} & Nuclear & 42 & 56.0 \\
\hline & Joint & 32 & 32.7 \\
\hline & extended & 1 & 1.3 \\
\hline \multirow[t]{3}{*}{7} & Employment status & & \\
\hline & Agriculturist/tailoring & 52 & 69.3 \\
\hline & House wife/coolie & 23 & 30.7 \\
\hline \multirow[t]{3}{*}{8} & Income of the family per month in rupees & & \\
\hline & $\leq 2500$ & 46 & 61.3 \\
\hline & $2501-5000$ & 29 & 38.7 \\
\hline \multirow[t]{5}{*}{9} & Information received on health and illness & & \\
\hline & Health personnel & 65 & 86.7 \\
\hline & Neighbor/friends & 39 & 52.0 \\
\hline & Family member & 51 & 68.0 \\
\hline & Mass media & 58 & 77.3 \\
\hline
\end{tabular}

adults of rural areas, perceived that smoking, alcohol intake, drug abuse, using unsafe water and food and multiple sex partner were the high risk for the health and illness. $26 \%$ of them reported leprosy/TB caused due to their past sins, $48 \%$ believed that epilepsy are due to ghost intrusion, 38\% had given the report illness can be traced by enemies and $36 \%$ adults perceived that diseases are caused by their 'karma'. Cultural and religious distance are essential for understanding self-care practice and careseeking behaviour, and need to be considered in the planning of care.

Table 2: Health seeking behavior:

\begin{tabular}{|c|c|c|c|}
\hline \multicolumn{2}{|c|}{ SI.No Area } & $f$ & $\%$ \\
\hline \multirow[t]{4}{*}{1} & Perception of own health & & \\
\hline & Good & 30 & 40.0 \\
\hline & Average & 43 & 57.3 \\
\hline & Poor & 02 & 2.7 \\
\hline \multirow[t]{4}{*}{2} & Decision taking to seek medical help & & \\
\hline & Parents & 17 & 23.6 \\
\hline & self & 53 & 70.0 \\
\hline & siblings & 05 & 6.4 \\
\hline \multirow[t]{5}{*}{3} & During illness where do you take treatment & & \\
\hline & Public centres/hospitals & 7 & 9.3 \\
\hline & Private hospitals & 27 & 36.0 \\
\hline & Nursing homes/clinics & 36 & 48.0 \\
\hline & Home remedies & 5 & 6.7 \\
\hline \multirow[t]{10}{*}{4} & Reason for not seeking health care & & \\
\hline & Feeling that diseases are not severe enough & 53 & 70.7 \\
\hline & Unable to pay medical expenses & 47 & 62.7 \\
\hline & Unreasonable charges in medical institution & 24 & 32.0 \\
\hline & Knowing how to deal with disease themselves & 28 & 37.3 \\
\hline & Having no free time & 26 & 34.7 \\
\hline & Long distance from medical institution & 13 & 17.3 \\
\hline & Complicated medical procedures & 25 & 33.3 \\
\hline & Long queuing and waiting time & 32 & 42.7 \\
\hline & Poor services & 3 & 4.0 \\
\hline
\end{tabular}

Fig 1: Perception score on health and IIIness (\%)

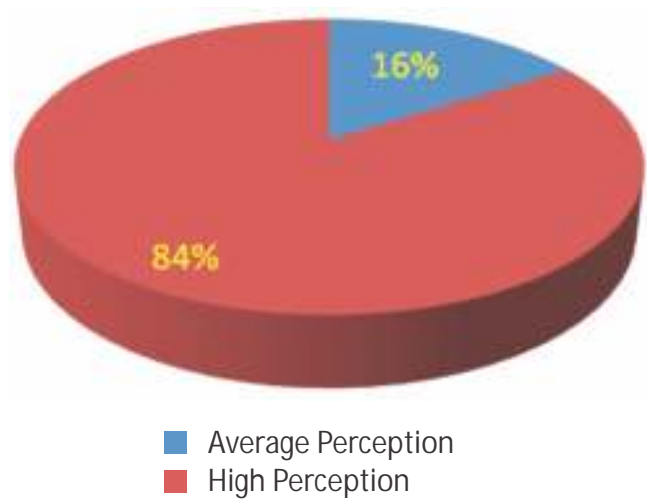


Table 3: Perception on health and illness:

SA: Strongly Agree (4), A: Agree (3) D: Disagree (2), SD: Strongly Disagree (1).

\begin{tabular}{|c|c|c|c|c|}
\hline Areas & SA & A & D & SD \\
\hline Perception on Health: & $\%$ & $\%$ & $\%$ & $\%$ \\
\hline Health is a complete state of physical, mental and social wellbeing & 81.3 & 18.7 & & \\
\hline Health is promoting a positive attitude & 33.3 & 35 & 18.7 & 1.3 \\
\hline Health is actively seeking out things that make me happy & 49.3 & 44 & 6.7 & \\
\hline Health is taking charge of and responsibility for, my own life & 29.3 & 56 & 12 & 2.7 \\
\hline I believe health is finding ways to resolve any inner conflicts & 26.7 & 54.7 & 16 & 2.7 \\
\hline Health is thinking positively and seeing the illness as challenge & 28 & 40 & 30.7 & 1.3 \\
\hline I believe health means looking after myself and taking things easy & 32 & 50.7 & 16 & 1.3 \\
\hline I believe health means giving up unhealthy habits & 45.3 & 34.7 & 17.3 & 2.7 \\
\hline I believe home prepared foods are good for health & 81.3 & 9.3 & 9.3 & \\
\hline I believe yoga/meditation is good for health & 88 & 10.7 & 1.3 & \\
\hline I believe exercises reduces the health risk & 66 & 32 & 1.3 & \\
\hline \multicolumn{5}{|l|}{ Perception on illness: } \\
\hline IIIness/diseases are caused by wrath of the god/goddess & 16 & 45.3 & 29.3 & 9.3 \\
\hline Venereal diseases are caused due to illicit sexual intercourse & 10.7 & 36 & 38.7 & 14.7 \\
\hline HIV/AIDS caused among poor socio economic people & 49.3 & 30.7 & 14.7 & 5.3 \\
\hline Leprosy and tuberculosis caused due to their past sins & 29.3 & 26.7 & 36 & 8 \\
\hline Children are most susceptible to the effect of 'evil eye' & 20 & 34.7 & 36 & 9.3 \\
\hline Childhood diseases are attributed to the anger of god. & 40 & 36 & 22.7 & 1.3 \\
\hline Hysteria or epilepsy (fits) are due to ghost intrusion & 40 & 48 & 10.7 & 1.3 \\
\hline Illness can be traced by enemies & 38.7 & 36 & 22.7 & 2.7 \\
\hline Illness can be prevented by eating certain types of foods. & 14.7 & 45.3 & 30.7 & 9.3 \\
\hline Foods such as meat, egg, fish are considered to generate heat & 14.7 & 20 & 37.3 & 28 \\
\hline Foods such as curds, milk, vegetables are believed to cool the body. & 8 & 20 & 21.3 & 50.7 \\
\hline Fasting leads to nutritional deficiency disorder & 17.3 & 28 & 33.3 & 21.3 \\
\hline Alcohol intake causes illness & 62.7 & 29.3 & 2.7 & 5.3 \\
\hline Passive smokers more prone to get certain diseases & 28 & 53.3 & 13.3 & 5.3 \\
\hline Poor ventilated houses causes diseases. & 41.3 & 40 & 14.7 & 4 \\
\hline Some diseases are caused by my 'karma'. & 32 & 30.7 & 25.3 & 12 \\
\hline Some diseases are inherited & 22.7 & 52 & 14.7 & 10.7 \\
\hline IIIness has serious financial consequences & 70.7 & 18.7 & 9.3 & 1.3 \\
\hline Some illness strongly affects the way the patient sees himself as a person. & 14.7 & 61.3 & 21.3 & 2.7 \\
\hline Illness makes me feel afraid and angry & 62.7 & 29.3 & 1.3 & 6.7 \\
\hline
\end{tabular}

Table 4: Perceived health risk

\begin{tabular}{|l|l|c|c|c|}
\hline SI No & Risks & Low risk & Moderate risk & High risk \\
\hline & & $(\%)$ & $(\%)$ & $(\%)$ \\
\hline 1 & Active smoking & 2.7 & 4.0 & 93.3 \\
\hline 2 & Passive smoking & 9.3 & 62.7 & 28.0 \\
\hline 3 & Alcohol intake & 4.0 & 10.7 & 85.3 \\
\hline 4 & Extreme water change & 30.7 & 56.0 & 13.3 \\
\hline 5 & Drug abuse & 1.3 & 36.0 & 62.7 \\
\hline 6 & Soil and road dust & 37.3 & 45.3 & 17.3 \\
\hline 7 & Eating junk foods & 21.3 & 45.3 & 33.3 \\
\hline 8 & Vehicle emission & 25.3 & 37.3 & 37.3 \\
\hline 9 & Over crowding & 14.7 & 62.7 & 22.7 \\
\hline 10 & Garbage burning & 38.7 & 49.3 & 12.0 \\
\hline 11 & Odor from garbage & 24.0 & 62.7 & 10.7 \\
\hline 12 & Wood as a cooking fuel & 58.7 & 34.7 & 6.7 \\
\hline 13 & Industrial emission & 1.3 & 56.0 & 42.7 \\
\hline
\end{tabular}


Table 4: Perceived health risk ( continued )

\begin{tabular}{|l|l|c|c|c|}
\hline SI No & Risks & Low risk & Moderate risk & High risk \\
\hline & & $\left(\begin{array}{l}\text { (\%) } \\
\text { (\%) }\end{array}\right.$ & (\%) \\
\hline 14 & High tension/stress & 10.7 & 52.0 & 37.3 \\
\hline 15 & Using unsafe water \& food & 0 & 22.7 & 76.0 \\
\hline 16 & Open electric wire & 37.3 & 32.0 & 30.7 \\
\hline 17 & Multiple sex partner & 5.3 & 36.0 & 58.7 \\
\hline 18 & Obesity & 17.3 & 44.0 & 37.3 \\
\hline 19 & Improper personal hygiene & 12.0 & 45.3 & 42.7 \\
\hline 20 & Noise & 42.7 & 52.0 & 5.3 \\
\hline 21 & Poor diet & 20.0 & 64.0 & 16.0 \\
\hline 22 & Emotional status & 14.7 & 70.7 & 14.7 \\
\hline 23 & Over work & 2.7 & 61.3 & 36.0 \\
\hline 24 & Ageing & 8 & 49.3 & 41.3 \\
\hline 25 & Immunity & 10.7 & 3344 & 44.0 \\
\hline 26 & Family problem & 13.3 & 52 & 33.3 \\
\hline 27 & Hereditary & 28.0 & 46.7 & 25.0 \\
\hline
\end{tabular}

Table 5: Association between perceived health \& illness and selected variables

\begin{tabular}{|c|c|c|c|c|c|}
\hline SI.No & Category & $\begin{array}{c}\text { Average } \\
\text { Perception }\end{array}$ & $\begin{array}{c}\text { High } \\
\text { Perception }\end{array}$ & $\chi^{2}$ & P value \\
\hline \multirow[t]{4}{*}{1} & Age in years & & & \multirow{4}{*}{2.97} & \multirow{4}{*}{.22} \\
\hline & $25-40$ & 6 & 46 & & \\
\hline & $41-60$ & 6 & 16 & & \\
\hline & $>60$ & 0 & 1 & & \\
\hline \multirow[t]{3}{*}{2} & Gender & & & \multirow{3}{*}{1} & \multirow{3}{*}{.63} \\
\hline & Male & 4 & 21 & & \\
\hline & Female & 8 & 42 & & \\
\hline \multirow[t]{4}{*}{3} & Religion & & & \multirow{4}{*}{2.57} & \multirow{4}{*}{.27} \\
\hline & Hindu & 12 & 56 & & \\
\hline & Muslim & 0 & 6 & & \\
\hline & Christian & 0 & 1 & & \\
\hline \multirow[t]{3}{*}{4} & M arital status & & & \multirow{3}{*}{2.96} & \multirow{3}{*}{.23} \\
\hline & Married & 12 & 55 & & \\
\hline & Unmarried & 0 & 8 & & \\
\hline \multirow[t]{4}{*}{5} & Educational status & & & \multirow{4}{*}{4.62} & \multirow{4}{*}{.099} \\
\hline & Primary $\left(>5^{\text {th }} \mathrm{std}\right)$ & 7 & 31 & & \\
\hline & Primary $\left(5^{\text {th }}\right.$ to $7^{\text {th }}$ Std $)$ & 5 & 20 & & \\
\hline & secondary & 0 & 12 & & \\
\hline \multirow[t]{4}{*}{6.} & Type of family & & & & \\
\hline & Nuclear & 8 & 34 & \multirow{3}{*}{.739} & \multirow{3}{*}{.390} \\
\hline & Joint & 34 & 28 & & \\
\hline & extended & 0 & 1 & & \\
\hline \multirow[t]{3}{*}{7} & Employment status & & & \multirow{3}{*}{.763} & \multirow{3}{*}{.519} \\
\hline & Agriculturist/tailoring & 6 & 6 & & \\
\hline & House wife/coolie & 40 & 23 & & \\
\hline \multirow[t]{3}{*}{8} & Income of the family per month in rupees & & & \multirow{3}{*}{.305} & \multirow{3}{*}{.742} \\
\hline & $\leq 2500$ & 7 & 42 & & \\
\hline & $2501-5000$ & 5 & 21 & & \\
\hline
\end{tabular}




\section{References}

1. Irena P. An Exploration of Health Beliefs, Lifestyle Behaviours, and Health Needs of the London-Based Greek Cypriot Community. Middlesex University Journal of Transcultural Nursing, Vol. 11 No. 3, June 2000 182-190

2. S. Kamalam. Essentials in community health nursing practice. $1^{\text {st }}$ edition. Jaypee brother medical publishers; New Delhi, 2005.

3. Haron Y, Rikva E, Linn S. Traditional belief concerning health and illness among members of circassiam community in Israel. Journal of Religion and Health vol. 43, no.1; 2004 Springer

4. Bettina F. Piko and Judit Bak. Children's perceptions of health and illness: images and lay concepts in preadolescenc. Health Educ. Res. (2006) 21 (5): 643-653.

5. «ttp://www.encyclopedia.com>.

6. Hjelm and M ufunda Zimbabwean diabetics' beliefs about health and illness: an interview study BMC International Health and Human Rights 2010, 10:7

7. Katarina Hjelm, Karin Bard, Per Nyberg and J an Apelqvist Religious and cultural distance in beliefs about health and illness in women with diabetes mellitus of different origin living in Sweden International Journal of Nursing Studies Volume 40, Issue 6, August 2003, Pages 627 643

8. Sushila Jain and Seema Agrawal Perception of Illness and Health Care Among Bhils: A Study of Udaipur District in Southern Rajasthan Stud. Tribes Tribals, 3(1): 15-19 (2005)

9. Catharine Wang and Elliot J Coup Beliefs about the causes of obesity are associated with physical activity and dietary behaviors of individuals in the general population. International Journal of Behavioral Nutrition and Physical Activity 2010, 7:19 